Collection: COST Action FP0905

"Biosafety of forest transgenic trees and EU policy directives"

Guest Editors: Cristina Vettori, Matthias Fladung

\section{Fifteen years of forest tree biosafety research in Germany}

\section{Matthias Fladung, Hans Hoenicka}

Since beginning of 1990 , several projects on biosafety research were initiated in Germany with genetically modified plants. Germany was also one of the first countries active on biosafety research with genetically modified trees (GMTs). An EU-funded project coordinated by the Institute of Forest Genetics (Johann Heinrich von Thuenen Institute, Grosshansdorf), from 1994 to 1997, was the first project of this kind in Germany. In the frame of this project, transgene stability was studied under greenhouse conditions in different transgenic aspen clones. A high degree of transgene expression stability was found in transgenic lines, however, gene silencing was detected in some transgenic plants. In Germany, the jump of the GMTs from the greenhouse to the field was initiated in 1996 by the Institute of Forest Genetics (Grosshansdorf), when the first field trial with genetically modified (GM) poplar was approved for five years. In the year 2000 and in cooperation with the University of Tuebingen, the same institute established a second field trial with GM poplar to study possible horizontal gene transfer (HGT) from the transgenic poplar into mycorrhizal fungi. No HGT was detected in those studies. Two further national funded projects on phytoremediation and status of mycorrhizal fungi in GMTs under field conditions were run by the University of Freiburg on $2002-2004$ and $2003-2005$. Topics of national funded biosafety research projects on GMTs released to the field but as well on greenhouse grown plants were transgene stability, genetic containment, transgene influence on mycorrhizal and phytopathogenic fungi, generative and vegetative propagation capacity, and horizontal gene transfer.

Keywords: Genetically Modified Trees, GMTs, GM Poplar, Field Trial, Risk Assessment, Mycorrhiza, Phytopathogenic Fungi, Horizontal Gene Transfer, Gene Stability

\section{Introduction}

Gene technological methods have been employed for genetic improvement of plants since the 1980s. Methods initially developed to characterize and modify annual plants are also being applied to forest trees. A number of different qualitative and quantitative fea-

Johann Heinrich von Thuenen Institute, Institute of Forest Genetics, Sieker LandstraBe 2, D-22927 Grosshansdorf (Germany)

@) Matthias Fladung

(matthias.fladung@vti.bund.de)

Received: Jan 24, 2012 - Accepted: May 23, 2012

Citation: Fladung M, Hoenicka H, 2012. Fifteen years of forest tree biosafety research in Germany. iForest 5: 126-130 [online 2012-06-13] URL: http://www.sisef.it/iforest/contents? id =ifor0619-005 tures have been identified in trees that can be improved with gene technological methods, e.g., lignin content, tree growth rate, and insect resistance. However, forest trees differ to annual plants in a number of characteristics, e.g., high age (100-1000 years), long vegetative phases, relatively slow growth rates, and out-crossing capacity. Therefore, when dealing with genetically modified (transgenic) trees (GMTs) several aspects of plant biosafety research, like genetic, biotic and/or trophic Interactions with symbiotic, parasitic or neutral organisms, vertical (VGT) and horizontal gene transfer (HGT), as well as tree specific issues, like stability and expression of foreign genes (transgenes) over a long period of time or root suckering, should be considered.

Several factors have to be managed during deliberate release of GMTs in order to avoid additional biosafety risks, e.g., vegetative propagation capacity (root suckering) and flower formation (potential VGT). The risk of a VGT can be minimized when transgenic lines contain the gene of interest (GOI) and a gene leading to male and/or female sterility or even to suppressed flower formation.

Many risk assessment studies have been carried out under controlled greenhouse and growth chamber conditions. However, these studies cannot substitute field releases, as they do not simulate the variability and complexity degree found in natural environmental conditions (Walter et al. 2010). Therefore, more than 700 different field experiments with GM trees have been established during the last 20 years worldwide (Robischon 2006, Walter et al. 2010).

\section{Biosafety research linked to} deliberate field releases of GMTs

In Germany, the first field release experiment with genetically modified trees was initiated by the Johann Heinrich von Thuenen Institute, Institute of Forest Genetics, Grosshansdorf, in 1996. The plant material employed for this first field trial was transgenic aspen (Populus tremula L.) and hybrid aspen (P. tremula L. $x$ P. tremuloides Michx.) containing the rolC gene from Agrobacterium tumefaciens under control by a viral (constitutive, 35S) or plant (light-inducible, rbcS) promoter. The permission for this field trial was given for five years from spring 1996 until autumn 2001. In total, eight transgenic aspen clones comprising the two mentioned gene constructs 35S::rolC (aspen lines Esch5, Brauna11, W52) and rbcS::rolC (aspen line Esch5), and the three control lines were planted out on a field of approximately $1500 \mathrm{~m}^{2}$ in size. The transgenic trees were measured with respect to growth (height, stem diameter, leaf size) and physiological parameters (dormancy, flushing, flower formation, hormone levels, and leaf metabolites). Formation of flower buds was monitored during the five years of duration of the field trial. Flower buds were detected in the third year of the field experiment. All flower buds, found exclusively on female $35 \mathrm{~S}::$ rolC transgenic poplar (clone Esch5), were removed, thus no flower bud developed into a mature flower.

Linked to that field trial, a national funded project termed "Gene Stability" aimed research on stability of foreign genes in tree genomes under natural environmental conditions. In general, rolC expression was stable in most transgenic plants. However, phenotypic instability in single plants, detected as reversions from the dwarfy phenotype of the $35 \mathrm{~S}:$ : rolC transgenic trees to wild type, was investigated using molecular methods. Based on these results, quick molecular methods were developed for assessing the stability/instability of foreign genes in transgenic trees on a genomic level (Kumar \& Fladung 2000). Molecular data comprised sequence analysis from the transgene-insertion locus 
as well as from transgene flanking regions (Fladung 1999). The investigations were extended to stable and unstable transgene expressing plants from the greenhouse.

Various examples of reversions from rolCto wildtype phenotype possibly suspecting transgene instability (unstable or variable expression of $\mathrm{rolC}$ ) were detected. One example of reversion occurred very often in greenhouse grown plants propagated from one independent transformed line but never during in vitro growth. Here, we could lead back the cause of the reversion to the molecular structure of the T-DNA insertion locus, revealing an incomplete inverted repeat (Fladung 1999), possibly leading to increased methylation of the promoter (Kumar \& Fladung 2000). In contrast, a second example was observed once as a single event in one bud of a particular 35S::rolC transgenic aspen plant during flushing in the greenhouse. Molecular analysis of this line revealed two independent transgene integration sites, with one site having an incomplete inverted repeat lacking the rolC gene $(\mathrm{Ku}-$ mar \& Fladung 2001a). Both examples described above, but also some others, have led to the hypothesis that transgene repeats influence transgene expression differentially among different transgenic lines (Fladung \& Kumar 2002).

The second important question addressed the mycorrhizal status of the tree roots possibly influenced by the transgenic status of the trees. The aims of this project were: (a) to study the colonisation of ectomycorrhizal (EM) fungi in transgenic and non-transgenic aspen grown in the field; and (b) to investigate a possible horizontal gene transfer from roots of the transgenic aspen to the EM fungi. In the first two years (1998/1999) no significant difference in EM colonisation and EM diversity was found between transgenic and control aspen with one exception (Kaldorf et al. 2002). Significant differences were found only for one EM type in respect to development and frequency which is a clonal effect in one transgenic line. In 2000/ 2001 an increase of EM diversity was found for control aspen but not for the transgenic aspen with constitutive rolC expression. The difference was not restricted to one line but to all four lines, thus it was construct-specific (Kaldorf et al. 2002).

In a third project, the above mentioned eight 35S::rolC and rbcS::rolC transgenic as well as wildtype aspen lines grown in the field trial were recorded for presence of phytopathogenic fungi (Fladung et al. 2004). The analyses on plants in the field revealed that in total eleven pathogenic and two saprophytic fungi were present mostly with higher levels (e.g., Pollacia, Marssonina, Melampsora) on both transgenic as well as on non-transgenic aspen trees. Fungi of the order Capnodiales were found in much high- er levels on leaves from 35S::rolC transgenic than on rbcS::rolC transgenic and control aspen. Further, the susceptibility towards the phytopathogenic fungi, Melampsora and Pollaccia radiosa, was studied on leaves from field grown transgenic aspen and nontransgenic controls using a special evaluation technique (Fladung \& Gieffers 2003). Results showed that infection rates with Melamspora were higher than with $P$. radiosa. However, two transgenic lines were more resistant against leaf rust than nontransgenic controls. All other transgenic lines showed no similar resistance. Infection tests with $P$. radiosa under controlled conditions revealed significant correlations to leaf spot disease in the field (Fladung \& Gieffers 2003).

Levels of leaf-metabolites such as glucose, fructose, saccharose, starch as well as different phytohormones were determined on field-grown transgenic and non-transgenic aspen trees. Higher levels of some leaf metabolites (e.g., monosaccharides) were found in 35S::rolC transgenic aspen compared to controls. These results were correlated to higher infection rates with phytopathogenic fungi. Higher infection rates of the Capnodiales fungi on leaves of the 35S:: rolC transgenic trees could be explained by this finding, because these fungi are often associated with the sugary honeydew secreted by leaf aphids.

Finally, the occurrence of root suckers putatively developed from roots of transgenic and non-transgenic trees was studied in the years 4 and 5 after establishment of the field trial. An increasing number of root suckers was found. Molecular analyses confirmed that root suckers were developed by wild type and rbcS::rolC but not by $35 \mathrm{~S}::$ rolC transgenic aspen trees (Fladung et al. 2003).

Plant material from the eight $35 \mathrm{~S}::$ rolC and rbcS::rolC transgenic as well as wildtype aspen lines grown in the field trial, harvested at the end of the field trial in October 2001, was subjected to different wood property tests. The wood samples were analyzed for: (a) wood's ultrastructure; (b) chemical content (lignin, cellulose); and (c) physical-technical properties (e.g., strength). Microscopic studies of the cambium and xylem revealed that 35S:: rolC transgenic lines have very thin year rings, compared to non-transgenic Esch5 controls and rbcS::rolC transgenic lines (Schmitt 2003). RbcS::rolC transgenic poplars as well as the controls had late wood fibres with much thickened cell walls in the xylem near the cambium, while the $35 \mathrm{~S}:$ :rolC transgenic lines often showed late wood fibres with less thickened walls (Schmitt 2003). Lignin pyrolysis products and scaffold polysaccharides were analysed (Meier et al. 2003). Combined with a multivariate primary component analysis, the spectrum of different lignin pyrolysis pro- ducts made it possible to differentiate the wood tissue of both, the control samples and the rbcS::rolC transgenic lines from the 35S::rolC transgenic aspens. Moreover, in spite of comparatively high fluctuations within the collective of the unmodified Esch5 controls as well as the rbcS::rolC and $35 \mathrm{~S}:$ :rolC transgenic aspens, results suggested that the wildtype trees possessed a higher amount of scaffold polysaccharides than the transgenic trees (Meier et al. 2003. Puls et al. 2003). These differences were especially distinct in the cellulose content (Puls et al. 2003). Interestingly, the transgenic 35S:: rolC transgenic aspens contained roughly $4 \%$ more Klason lignin. This finding was explained by results of the physical examination of the wood, which showed that $35 \mathrm{~S}:$ : rolC transgenic aspens have increased raw densities compared to rbcS::rolC transgenic and control plants (Schwab \& Krause 2003). In 2000, a second field release experiment with genetically modified aspen was initiated for three years by the Institute of Forest Genetics (Grosshansdorf) in cooperation with the University of Tuebingen. The aim of this field release experiment was the detection and quantification of possible horizontal gene transfer (HGT) events taking place from transgenic trees into mycorrhizal fungi. (Nehls et al. 2006). In nature, ectomycorrhizal fungi are symbionts tightly associated with the root system of trees. Thus, to investigate horizontal gene transfer from aspen to ectomycorrhizal fungi under natural conditions, transgenic trees containing the bar gene (conferring BASTA resistance) were released in a field experiment (Nehls et al. 2006). Even when a horizontal gene transfer event is more likely in mycorrhizal symbiosis compared to saprophytic interactions, no HGT from transgenic aspen into ectomycorrhizal fungi was detected, neither under optimized laboratory nor under field conditions (Nehls et al. 2006). In this three-year study, after examination of about 100.000 different mycorrhiza/root structures, no evidence of a horizontal gene transfer could be found.

Two additional field trials with GM poplars were established by the University of Freiburg in 2002 and 2003, both taking place in Saxony-Anhalt, Germany, for three years each. The aim of both field trials was the assessment of phytoremediation capacity and biosafety risks of transgenic poplar grown on soils contaminated with heavy metals (Peuke \& Rennenberg 2006). The released transgenic poplars over-expressed the glutathione synthetase gene ( $g s h I)$ from $E s$ cherichia coli. Therefore, transgenic plants showed increased levels of glutathione in the cytosol. Glutathione is known as an active component in the plant cell for poison detoxification. In the two field trials in Saxony-Anhalt, the level of glutathione production in various GM poplar lines as well as 
their capacity for removal of heavy metals (here: copper) at different levels of contamination was determined under different climatic conditions. A similar field trial was established in Russia (Middle Urals, Swerdlovsk oblast) also in a copper mining area. The results indicate that the transgenic trees reveal a higher capacity for heavy metal accumulation on the most highly contaminated soils. However, no differences could be found on sites with low heavy metal contamination (Peuke \& Rennenberg 2006).

\section{Biosafety research with GMTs in the lab and greenhouse}

Research activities on biosafety of GMTs were first initiated by the Johann-Heinrich von Thünen Institute (vTI), Institute of Forest Genetics (Grosshansdorf) in 1993. An EU-funded biosafety project (AIR2-CT941571 ) entitled "Gene stability in forest trees" was established in 1994, coordinated by the Institute of Forest Genetics, Grosshansdorf. Participants in this EU-project were Gilles Pilate (France), Olle Olsson (Sweden), M Raj Ahuja (Germany), and Matthias Fladung (Germany). Along this project, differen 35S::rolC and rbcS::rolC transgenic aspen (Populus tremula) and hybrid aspen ( $P$. tremula L. $x$ P. tremuloides Michx.) lines were used to study gene stability under greenhouse conditions. Results showed in general a high degree of genetic stability of the rolC marker gene in transgenic aspen. However, phenotypic variations in some transgenic lines, caused by rolC silencing, could be correlated to genomic changes involving T-DNA.

Complete or partial elimination of T-DNA can reduce biosafety risks derived from transgenic plants. Therefore, one approach was tested for targeted insertion of transgenes and simultaneous removal of the marker gene using site-specific recombination systems. Integration of the transgene into the host genome during the transformation process occurs randomly and in a non-predictable copy numbers, many times in the form of repeats. The integration site often has a profound effect on transgene expression which can be amplified when the transgene insertion is made homozygous during the breeding process. To address the issue of expression variability, suggestions on controlling transgene integration in plants have been made very early (Kumar \& Fladung 2001b). Antibiotic or herbicide selection marker genes are needed to control success of the transformation process. However, increased biosafety risks derived from antibiotic resistance genes have been proposed (Hoenicka \& Fladung 2006).

Site-specific recombination (SSR) systems can be used to place a recognition target (reporter gene) within the genome, so that the "gene-of-interest" (GOI) can be precisely placed into the target, but also to eliminate genes, e.g., antibiotic marker gene. The aim of this research area was to test the usability of the bacterial cre/lox and yeast FLP/FRTrecombination systems in transgenic poplar (Fladung et al. 2010). The activity of the FLP-recombinase was controlled by a soybean (Glycine max) heat-shock promoter. We could show that after the activation of the FLP-recombinase by heat, this enzyme recombined at two collateral orientated $F R T$ sites. For a "proof-of-concept" of targeted integration, we aimed replacing the selection marker $n p t I I$ with a promoterless bar gene located on a second T-DNA (Fladung et al. 2010). Following heat-shock-induced recombination, the nptII gene disappeared and the bar gene replaced it in the T-DNA, thus became active under control of the 35S-promoter. Targeted events could therefore easily be detected in BASTA resistance tests. Southern blot experiments and sequencing analyses have confirmed successful targeting of the bar gene. Success of marker gene elimination was controlled in GUS staining tests by use of a promoterless uidA reporter gene located at one $F R T$-site which gets under the control of the CaMV35S-promoter located at the second FRT-site following the recombination process (Fladung et al. 2010).

A major concern over the use of transgenic trees is the potential vertical gene transfer (VGT) followed by extensive transgene dispersal through pollen and seeds. The incorporation of sterility genes into transgenic tree lines has been proposed to reduce or even avoid gene flow of transgenes into nontransgenic relatives, which is one of the main ecological concerns with respect to commercial use of transgenic plants. The evaluation of strategies for the induction of sterility in transgenic forest tree species has been hindered by their long vegetative periods, reaching in poplar more than seven years, and even 40 years for example in beech. We initiated research aiming genetic containment of transgenic poplar in a research project funded by the German government (BMBF) from 2002 to 2006. First of all, we evaluated different strategies for accelerating the reproductive phase in poplar. Treatment with different chemicals and genetic transformation with some flowering time genes, which have been successful in other trees species, were not successful in poplar. However, use of the $35 \mathrm{~S}:: L F Y$ gene construct allowed obtaining flowers and pollen grains under greenhouse conditions. Early flowering $35 \mathrm{~S}:: L F Y$ poplar lines were transformed with different gene constructs aiming the avoidance of pollen development. The combination of two transgenic approaches, one to induce early flowering and a second one for the induction of sterility, allowed evaluation of sterility strategies two years after transformation (Hoenicka et al. 2006). Early flowering male poplar plants carrying different sterility gene constructs were transferred to the greenhouse between 2004 and 2006 . Several of these lines flowered in the growth chamber and were investigated in respect to the expression of the sterility constructs. Genetic transformation of early flowering poplar with the sterility gene construct CGPDHC::Vst1 promoted a higher incidence of sterility in poplar flowers compared to early flowering controls (Hoenicka et al. 2006).

The early flowering model $35 \mathrm{~S}:: L F Y$ was the first one available for the evaluation of containment strategies in poplar. Unfortunately it has some drawbacks, like dwarf growth and sterility. Despite of positive FDA viability tests, no crossings were successful with pollen derived from $35 \mathrm{~S}:: L F Y$ transgenic lines. Genetic transformation of early flowering poplar with sterility constructs TA29::Barnase, CGPDHC::Barnase and TA29::PDH E1 $\alpha-A S$ had a strong detrimental effect on general performance of obtained transgenic lines, avoiding their long term survival under greenhouse conditions.

Genetic transformation of the hybrid aspen clone T89, with a natural shorter vegetative phase, with the MALE1::STS gene (Höfig et al. 2003) promoted sterility. However, first flowers can only be obtained four to five years after transformation. Therefore, some alternative early flowering models have to be developed in the future.

Flowering $T$ gene was incorporated 2005 into our biosafety program. The $35 \mathrm{~S}:: F T$ and HSP::FT gene constructs were used for genetic transformation. Both gene constructs allow induction of early flowering. However, only the heat inducible promoter (HSP) allowed a reliable flower induction. Early flowering HSP::FT poplar plants were incorporated into the current biosafety project initiated in 2008, also funded by the German government (BMBF), aiming the selective $\mathrm{T}$ DNA elimination from reproductive organs in poplar. This sophisticated approach to prevent VGT, based on recombination assisted gene elimination, is currently being tested in early-flowering transgenic poplar (Fladung \& Hoenicka 2009). The recombinase is activated during flower formation excising T-DNA only from the flower genome but not from the genome of all other plant tissues, thus the plant is still carrying the genetic modification.

Endophytic bacteria colonize inner host tissues, sometimes in high numbers, without damaging the host or eliciting strong defense responses (Reinhold-Hurek \& Hurek 2011). Unlike endosymbionts they are not residing in living plant cells or surrounded by a membrane compartment. The question whether a horizontal gene transfer from Agrobacterium to endophytic bacteria in poplar is possible was addressed under controlled conditions in a project carried out in the Institute of Forest 
Genetics (Waldsieversdorf). The composition of endophytic bacteria in field grown clones and in vitro propagation systems was characterized in initial studies. It could be shown that the endophyte community in the field poplar clones was very diverse (Ulrich et al. 2008a). Further, significant differences were found in endophyte diversity between poplar clones, depending from the location of cultivation. However, bacteria of the genus Paenibacillus dominated in most of the tissue cultures of woody plants (Ulrich et al. 2008b). As Paenibacillus is phylogenetically quite distinct from Agrobacterium, no common plasmids are known. No HGT event could be detected in vivo or in vitro between Agrobacterium and endophytic bacteria. Only the uptake of an external applied binary vector could be observed (Ewald \& Ulrich 2009a).

\section{Conclusions}

The promising prospects offered by gene technology, especially for tree breeding, have promoted the interest on using those methods with forest tree species. Tree species within the genera Populus (poplars), Picea (spruces), Pinus (pines) and Eucalyptus (eucalyptus) have genetically been modified with several gene constructs. However, due to biosafety concerns field releases of GM trees still remain very seldom. Questions have been formulated on the potential risks of the release of transgenic trees, in particular to the transfer of recombinant DNA into the gene pool of a given species via VGT. In many countries, biosafety research has been initiated to evaluate putative risks following the release of GM tress into the field. However, there is still a lack of information regarding biosafety on GM trees. The number of publications on this area is very low. Despite of some initial approaches for the evaluation of strategies for reduction of VGT from GM trees, there is a necessity for promoting research on this important issue. This article describes only the present state-of-the-art on biosafety research in Germany. However, field trials have been conducted in other countries as well. Those biosafety relevant results, which still are very scattered, will be compiled and analyzed in the frame of the ongoing EU-COST (European Cooperation in Science and Technology) Action FP0905, entitled "Biosafety of forest transgenic trees: improving the scientific basis for safe tree development and implementation of EU policy directives" (Fladung et al. 2012). The main objective of this COST Action is to evaluate and substantiate scientific knowledge relevant to the biosafety of GM trees. This COST Action will therefore support future European Union (EU) policy decisions on regulation of a safe development and practical use of GM trees.

\section{Acknowledgements}

Most projects described in this study were funded by the Federal Ministry for Research and Education (BMBF). We would like to thank the colleagues of the different projects for their scientific as well as our co-workers in the Institute of Forest Genetics namely Ebbinghaus D., Schellhorn A., Olaf Polak, Denise Lehnhardt, Gabi Bentien, Susanne Bein, D. Boedecker, M. Wellern, G. Wiemann, R. Ebbinghaus, and M. Spauszus for their valuable technical support.

This work has been presented at the "First Biosafety Workshop" of COST Action FP0905, held in Hamburg (Germany) on September $9^{\text {th }}, 2010$.

\section{References}

Ewald D, Ulrich K (2009). Transgenic poplars: is horizontal gene transfer from Agrobacteria to endophytic bacteria possible? [online] URL: http://www.gmo-safety.eu/database/1011.transgenic-poplars-horizontal-gene-transfer-agrobacteria-endophytic-bacteria-possible.html

Fladung M, Gieffers W (2003). Untersuchungen zum Hormon- und Kohlenhydrat-Metabolismus in rolC transgenen Aspenklonen und deren mögliche Auswirkungen auf phytopathologische Eigenschaften. In: "Holzbiologische, -chemische, -technologische und phytopathologische Untersuchungen an rolC-transgenen Hybridaspen $(P$. tremula L. x P. tremuloides Michx.) aus einem Freisetzungsversuch“ (Fladung M ed). Mitteilungen der Bundesforschungsanstalt für Forst- und Holzwirtschaft, Hamburg 214: 81-112.

Fladung M, Hoenicka H (2009). Preventing the spread of genetically modified poplars through transgene-free pollen. [online] URL: http://www. gmo-safety.eu/database/1058.preventing-spreadgenetically-modified-poplars-transgene-free-pollen.html

Fladung M, Kumar S (2002). Gene stability in transgenic aspen - Populus - III. T-DNA repeats influence transgene expression differentially among different transgenic lines. Plant Biology 4 (3): 329-338. - doi: 10.1055/s-2002-32329

Fladung M (1999). Gene stability in transgenic aspen (Populus). I. Flanking DNA sequences and T-DNA structure. Molecular and General Genetics 260 (6): 574-581. - doi: 10.1007/ s004380050931

Fladung M, Nowitzki O, Ziegenhagen B, Kumar S (2003). Vegetative and generative dispersal capacity of field released transgenic aspen trees. Trees - Structure and Function 17 (5): 412-416. doi: 10.1007/s00468-003-0253-3

Fladung M, Kaldorf M, Gieffers W, Ziegenhagen B, Kumar S (2004). Field analysis of transgenic aspen. In: "Plantation forestry of the $21^{\text {st }}$ century" (Walter C, Carson M eds). Research Signpost, pp. 393-403.

Fladung M, Schenk TMH, Polak O, Becker D (2010). Elimination of marker genes and targeted integration via FLP/FRT-recombination system from yeast in hybrid aspen (Populus tremula L. $\mathrm{x}$ P. tremuloides Michx.). Tree Genetics and Ge- nomes 6 (2): 205-217. - doi: 10.1007/s11295009-0241-X

Fladung M, Altosaar I, Bartsch D, Baucher M, Boscaleri F, Gallardo F, Häggman H, Hoenicka H, Nielsen K, Paffetti D, Séguin A, Stotzky G, Vettori C (2012). European discussion forum on transgenic tree biosafety. Nature Biotechnology 30: 37-38. - doi: 10.1038/nbt.2078

Hoenicka H, Fladung M (2006). Biosafety in Populus spp. and other forest trees: from nonnative species to taxa derived from traditional breeding and genetic engineering. Trees 20: 131144. - doi: 10.1007/s00468-005-0023-5

Hoenicka H, Nowitzki O, Debener T, Flaudung M (2006). Faster evaluation of induced floral sterility in transgenic early flowering poplar. Silvae Genetica 55 (6): 285-291. [online] URL: http://allgemeineforstundjagdzeitung.com/filead$\mathrm{min} /$ content/dokument/archiv/silvaegenetica/55 2006/55-6-285.pdf

Höfig K, Moyle R, Putterill J and Walter C (2003). Expression analysis of three Pine male cone promoters in the heterologous host $\mathrm{Ara}$ bidopsis. Planta 217: 858-867 - doi: 10.1007/ s00425-003-1057-9

Kaldorf M, Fladung M, Muhs HJ, Buscot F (2002). Mycorrhizal colonization of transgenic aspen in a field trial. Planta 214: 653-660. - doi: $10.1007 / \mathrm{s} 004250100658$

Kumar S, Fladung M (2000). Determination of TDNA repeat formation and promoter methylation in transgenic plants. BioTechniques 28: 11281137. [online] URL: http://cat.inist.fr/? aModele $=$ afficheN\&cpsidt $=1407500$

Kumar S, Fladung M (2001a). Gene stability in transgenic aspen (Populus). II. Molecular characterization of variable expression of transgene in wild and hybrid aspen. Planta 213: 731-740. doi: 10.1007/s004250100535

Kumar S, Fladung M (2001b). Controlling transgene integration in plants. Trends in Plant Science 6 (4): 155-159. - doi: 10.1016/S1360-1385 (01)01890-8

Meier D, Fortmann I, Odermatt J, Faix O (2003). Pyrolyse-GC/MS und Pyrolyse-GC/FID Untersuchungen an gentechnisch veränderten Pappelklonen. In: "Holzbiologische, -chemische, -technologische und phytopathologische Untersuchungen an rolC-transgenen Hybridaspen $(P$. tremula L. x $P$. tremuloides Michx.) aus einem Freisetzungsversuch“ (Fladung M ed). Mitteilungen der Bundesforschungsanstalt für Forst- und Holzwirtschaft, Hamburg 214: 33-43.

Nehls U, Zhang C, Tarkka M, Hampp R, Fladung $M$ (2006). Investigation of horizontal gene trans fer from transgenic aspen to ectomyccorhizal fungi. In: "Tree transgenesis - recent developments. (Fladung M, Ewald D eds). Springer-Verlag, Berlin, Heidelberg, New York, pp. 323-333. Peuke A, Rennenberg H (2006). Heavy metal resistance and phytoremediation with transgenic trees. In: "Tree transgenesis - recent developments"(Fladung M, Ewald D eds). Springer-Verlag, Berlin, Heidelberg, New York, pp. 137-155. Puls J, Reisen M, Saake B (2003). Vergleichende Untersuchungen zur Zusammensetzung der Zell- 
wandkomponenten gentechnisch veränderter Aspen. In: "Holzbiologische, -chemische, -technologische und phytopathologische Untersuchungen an rolC-transgenen Hybridaspen ( $P$. tremula L. $\mathrm{x} P$. tremuloides Michx.) aus einem Freisetzungsversuch“ (Fladung, M ed). Mitteilungen der Bundesforschungsanstalt für Forst- und Holzwirtschaft, Hamburg 214: 45-52.

Reinhold-Hurek B, Hurek T (2011). Living inside plants: bacterial endophytes. Current Opinion in Plant Biology 14: 435-43. - doi: 10.1016/j. pbi.2011.04.004

Robischon M (2006). Field trials with transgenic trees - state of the art and developments. In "Tree Transgenesis - Recent Developments" (Fladung M, Ewald D eds). Springer-Verlag, Berlin, Heidelberg, New York, pp. 3-23.
Schmitt U (2003). Mikroskopische Untersuchungen des Kambiums und Xylems von rolC transgenen Aspenklonen. In: "Holzbiologische, -chemische, -technologische und phytopathologische Untersuchungen an rolC-transgenen Hybridaspen $(P$. tremula $\mathrm{L}$. $\mathrm{x} P$. tremuloides Michx.) aus einem Freisetzungsversuch“ (Fladung $\mathrm{M}$ ed). Mitteilungen der Bundesforschungsanstalt für Forst- und Holzwirtschaft, Hamburg 214: 15-32.

Schwab E, Krause HA (2003). Holztechnologische Untersuchungen an gentechnisch veränderten Aspen. In: "Holzbiologische, -chemische, -technologische und phytopathologische Untersuchungen an rolC-transgenen Hybridaspen ( $P$. tremula L. x P. tremuloides Michx.) aus einem Freisetzungsversuch" (Fladung M ed). Mitteilun- gen der Bundesforschungsanstalt für Forst- und Holzwirtschaft, Hamburg 214: 53-80.

Ulrich K, Ulrich A, Ewald D (2008a). Diversity of endophytic bacterial communities in poplar grown under field conditions. FEMS Microbiology Ecology 63: 169-180. - doi: 10.1111/ j.1574-6941.2007.00419.x

Ulrich K, Stauber T, Ewald D (2008b). Paenibacillus - a predominant endophytic bacterium colonising tissue cultures of woody plants. Plant Cell, Tissue and Organ Culture 93: 347-351. doi: 10.1007/s1 1240-008-9367-z

Walter C, Fladung M, Boerjan W (2010). The 20year environmental safety record of GM trees. Nature Biotechnology 28: 656-658. - doi: 10.1038/nbt0710-656 